\title{
Mobil Oyun Yazılım Süreçlerinde Canlandırma Kütüphaneleri Kullanımının Değerlendirilmesi
}

\section{An Evaluation of Using Animation Libraries in Mobile}

\section{Game Software Processes}

\author{
Muzaffer TEPEKULE \\ Masomo Oyun Teknolojileri \\ A.Ş. Tasarım Merkezi, İzmir, \\ Türkiye \\ muzaffer.tepekule@masomo.com \\ ORCID: 0000-0001-7832-6025
}

\author{
Mehmet Ali SAKARYA \\ Masomo Oyun Teknolojileri \\ A.Ş. Tasarım Merkezi, İzmir, \\ Türkiye \\ mehmetali.sakarya@masomo.com \\ ORCID: 0000-0002-9829-9885
}

\author{
Rudi DIRIMAN \\ Masomo Oyun Teknolojileri \\ A.Ş. Tasarım Merkezi, \\ İzmir, Türkiye \\ rudi.diriman@masomo.com \\ ORCID: 0000-0002-5996-5507
}

\author{
Kaya OĞUZ \\ İzmir Ekonomi Üniversitesi, \\ Bilgisayar Mühendisliği Bölümü, \\ İzmir, Türkiye \\ kaya.oguz@ieu.edu.tr \\ ORCID: 0000-0002-1860-9127
}

\author{
Geylani KARDAŞ \\ Ege Üniversitesi, \\ Uluslararası Bilgisayar Enstitüsü, \\ İzmir, Türkiye \\ geylani.kardas@ege.edu.tr \\ ORCID: 0000-0001-6975-305X
}

\section{Öz}

Mobil oyunlarda canlandırma için hareketli grafik ve iki boyutlu iskelet canlandırma yaklaşımları kullanılmaktadır. Bu çalıșmada canlandırma yaklaşımlarının popüler iki mobil oyundaki canlandırmalar üretilirken kullanılmasına dair bir değerlendirme sunulmaktadır. Değerlendirme sonuçlarına göre iki boyutlu iskelet canlandırma kütüphanelerinin kullanımı ile canlandırma pozlarınin konumlandırılmasinın kolaylaştı̆̆ ve canlandırma kurgusunun kisa sürede geliştirici ve sanat ekipleri arasında paylaşıldiğını göstermiştir. Kütüphane kullanımının canlandırma üretimini ortalamada yaklaşık 12 kat arttırdiğı, canlandırma geliştirme sürecini ise yaklaşık $\% 65$ oranında kısalttı̆̆ belirlenmiştir. Ayrıca, çalışmada sanat ekibi canlandırma kütüphanesini canlandırmanın temel prensiplerine göre değerlendirmiştir.

Anahtar Sözcükler: Mobil oyun, Oyun yazılımı, Oyun yazllımı geliştirme süreci, canlandırma

Gönderme ve kabul tarihi: 24.11.2021 - 12.12.2021

Makale türü: Araştırma

\section{Abstract}

Sprites and two-dimensional skeletal animations are the most common approaches to provide animations in mobile games. In this study, these approaches are evaluated during the production of animations of two popular mobile games. The results show that twodimensional skeletal animation libraries made it easier to position animation poses and provided a quick way of sharing animations between the development and the art teams. Use of the animation library increased the creation of animations 12 -fold, and reduced the time to create animations by $65 \%$. The study also evaluates the animation library with respect to the 12 principles of animation.

Keywords: Mobile game, Game software, Game software development process, Animation

\section{Giriş}

Başlıca amaçları kullanıcılarını eğlendirmek ya da eğitmek olan bilgisayar oyunu yazılımlarının geliştirilmesinde yaygın kullanımdaki bilindik yazılım geliştirme yaşam döngülerini doğrudan 
uygulamak çoğu zaman yeterli gelmemektedir [1]. $\mathrm{Bu}$ yazılımların geliştirme süreçleri bilgisayar bilimleri, sanat, medya tasarım ve benzeri birçok disiplinden gelen kişilerin oluşturduğu geniş ekiplerin birlikte çalışmasına dayanır [2]. Süreç benzetim, grafik, yapay zekâ, fizik, ses programlama, ve çevrimiçi çok oyunculu oyunlar için ağ ve veri tabanı programlama bilgisi gerektiren karmaşık etkinlikleri içerir [3], [4].

Bir bilgisayar oyunun oluşturulmasında genellikle fikir, plan, tasarım, geliştirme ve test adımlarından oluşan bir süreç izlenmektedir [5]. Bu sürecin hemen hemen tüm adımlarında hem yaratıcı ihtiyaçların ve teknik kısıtlamaların birbirine etkisini yönetmek [6] hem de kullanıcıların ilgisini çekecek canlandırmaları (İngilizce animation) geliştirmek önemli bir yer tutmaktadır. Mobil oyun sektörünün çok rekabetçi olmasından dolayı firmalar oyun içerisinde bulunan karakterlerin özelliklerini ön plana çıkarmak adına daha fazla canlandırmaya sahip karakterleri oyuna eklemeye çalışmaktadır. Karakterlerde hareket algısını oluşturmak için $\mathrm{C}++$, $\mathrm{C} \#$ ve Java gibi genel amaçlı programlama dillerinin kullanıldığ 1 geleneksel yaklaşım yerini ilgili alana özel çeşitli yazılım kütüphanelerinin ve araçlarının sistematik kullanılmasına bırakmaktadır [7].

İki boyutlu (2B) oyunlarda yer alan karakterleri canlandırmak için iki temel yaklaşım vardır. İlki hareketli grafik (İngilizce sprite) adı verilen, hareketin her karesinin ayrı olarak çizildiği ve tüm karelerin tek bir görüntüde toplandığı yaklaşımdır [8]. Temel canlandirma prensibine dayanan bu yaklaşım, harekete ait karelerin belirli aralıklarla arka arkaya gösterilmesine dayanır. Her kare ayrı ayrı çizildiği için yazılım ile kontrolü var olan hareketlerle sinırlıdır. Yeni canlandırmaların eklenmesi için yeni çizimlerin yapılması gerekmektedir. Buna rağmen sık kullanılan ve Unity gibi güncel oyun geliştirme ortamlarında doğrudan desteği olan bir yaklaşımdır [9]. Diğer yaklaşım olan iki boyutlu iskelet canlandırmada, üç boyutlu modellerde olduğu gibi iskelete ait uzuvların birbirlerine sıradüzensel olarak bağlanması ve iskeletin farklı pozları arasındaki değişimlerin hesaplanması ile hareket algısı sağlanmaktadır [10]. $\mathrm{Bu}$ yaklaşım iskelete ait canlandırmaların farklı görüntülerle kullanılmasını, yeni hareketlerin çizilmesine gerek kalmadan oyuna dahil edilmesini, canlandırmalar arası yumuşak geçişleri ve yürürken ateş etmek gibi farklı canlandırmaların bir arada kullanılmasını sağlamaktadır.

$\mathrm{Bu}$ çalışma, iki boyutlu iskelet canlandırma kütüphanelerinin oyun geliştirme süreçlerine ait etkilerini değerlendirmek amaciyla daha önce Spine [11] kütüphanesi kullanılarak yapılan bir çalışmayı [12] genişletmektedir. Kapsam yönünden değerlendirmeye dâhil edilen oyun sayısı ve nicel çözümleme çeşitleri artırılmış, kütüphanelerin kullanımını "Canlandırmanın 12 Prensibi" [13] göz önüne alınarak değerlendirilmiştir. Her ne kadar canlandırma kütüphanelerini kapsayan çalışmalar (örneğin [10], [14], [15]) yayınlanmış olsa da bu kütüphanelerin ticari oyunların geliştirilmesi ihtiyacını ne ölçüde karşılayabildiğini göz önüne alan ve endüstriyel boyutta kullanımını değerlendiren bilimsel bir çalışmaya rastlanmamıştır. $\mathrm{Bu}$ eksiklikten hareketle, bu çalışmada Masomo Gaming firmasının tüm mobil ortamlarında en çok indirilen ve oynanan oyunlarının canlandırmalarının üretilmesi sırasında bir canlandırma kütüphanesinin kullanılmasına ait değerlendirme sunulmuştur. Proje ekiplerinin kütüphane kullanımına yönelik elde ettiği deneyimler aktarılmış, kütüphane kullanımının yararları ve sakıncaları gösterilmiştir.

Makalenin bir sonraki bölümünde var olan ilgili çalışmalar incelenmiştir. Üçüncü bölümde değerlendirmenin yapılabilmesi için kullanılan yöntem detaylı olarak anlatılmış, kütüphanelerin kullanımı nitel ve nicel olarak incelenmiş ve değerlendirilmiştir. Son bölümde ise elde edilen sonuçlar özetlenmiş ve yorumlanmıştır.

\section{2. İlgili Çalışmalar}

Günümüz mobil ortamlarının gerektirdiği rekabet ortamı öncesinde de oyun geliştirme, içerdiği yaratıcı süreçler nedeniyle, belirli kalıplar içerisine alınamamış, her ekip süreç içerisinde karşılaştığ1 problemleri kendilerine ve probleme özgü şekilde çözmüşlerdir [16]. Mobil oyunların hızlı tüketimi oyunların ömrünü kısaltmış, ama maliyetlerin ve riskin artmasına neden olmuştur. Maliyetleri ve riskin etkilerini azaltmak için hem yazılımın yeniden kullanılması sağlanmış, hem de sürekli yeni içerik sunularak oyunlar taze tutulmaya çalışılmıştır [17]. Bunların sağlanması için de belirli bir yazılım süreci değil, yine her ekibin kendi ürettiği çözümler kullanılmıştır [7].

Mobil oyunların önemli bileşenlerinden biri olan 
canlandırmalar için kullanılacak yöntemin hem yeni içeriğin oyuna dahil edilmesinde yazılım sürecinden en hızlı şekilde çıkmasını sağlaması, hem de mobil oyunların disk alanı ile ilgili kısıtlarını karşılayabilmesi gerekmektedir. Bu kısıtlar hareketli grafik temelli bir yaklaşımdan çok iki boyutlu iskelet canlandırmalarının mobil oyun geliştirme süreçlerine daha uygun olduğunu göstermektedir [10].

İki boyutlu iskelet canlandırmayı değerlendiren Lehtonen çalışmasında Spine, Spritter, Adobe Animate ve Toon Boom canlandırma yazılımlarını, iskelet canlandırma desteği, farklı oyun motorlarına aktarım olanakları, görüntü değișimleri, ters kinematik ve çizim araçları sunabilme ölçütlerini göz önünde bulundurarak bir ön değerlendirmeden geçirmiştir [10]. Bu ölçütlere göre Spine yazılımını en uygun kütüphane seçerek bir sanal müze gezintisi uygulamasının geliştirilmesinde kullanmıştır. Daha önceden hareketli grafik tabanlı öğe olarak bulunan canlandırmaların iskelet canlandırmalarına çevrimini de göstermiştir. Uygulamadan elde edilen tek değerlendirme sonucu hareketli grafik tabanlı canlandırmaya göre iskelet canlandırmaların daha pürüzsüz olduğudur.

Yapılan diğer çalışmalar arasında Ubillis [18] iOS tabanlı mobil oyunların geliştirilmesi sırasında SpriteKit [19] kullanımına ait deneyimleri aktarırken bir savaş sahnesinde yer alan karakterlerde iki boyutlu iskelet canlandırması kullanmıştır. Diğer bir çalışmada, Ciesla, iki boyutlu iskelet canlandırma kütüphanelerini mevcut dokümanları ve lanse edilen özellikleri üzerinden değerlendirmiștir [14]. Myller ise kütüphanelerin farklı oyun motorları için hazırlanma adımlarını göstermiștir [15]. Adları geçen çalışmalarda canlandırma yöntemlerinin yazılım geliştirme süreçlerine yönelik bir değerlendirmesi yoktur.

Bu çalışma ile büyük çaplı ticari oyun yazılımlarının geliştirme süreçlerinde iki boyutlu iskelet canlandırmaları kullanılmasından elde edilen deneyimler ve değerlendirmeler sunulmaktadır. $\mathrm{Bu}$ konuda deneyimlerini paylaşan başka bir çalışmaya rastlanmamıştır. Elde edilen sonuçların hızla gelişen oyun pazarındaki geliştiricilerin mevcut oyunlarını iyileştirme veya yeni oyunları geliştirme süreçlerinde canlandırma kütüphanelerinin seçimine katkı sağlayacağına inanıyoruz. Ayrıca, oyun yazılım geliştirme süreçlerinin incelenmesi ve iyileştirmesi ile ilgili deneyimlerin belgelenmesine yardımcı olmasını bekliyoruz.

\section{Yöntem}

Canlandırma kütüphanelerinin oyun geliştirme sürecine katkılarını incelemek için bu çalışmada öncelikle canlandırmaların geliştirme sürecindeki yerleri incelenmiştir. $\mathrm{Bu}$ bağlamda geliştirici, tasarım ve sanat ekiplerinden elde edilen geri bildirimlerle canlandırma kütüphanelerinin oyun içeriği üretimine katkıları hem nicel olarak üretilen canlandırma sayısıyla, hem de nitel olarak canlandırma prensiplerine göre değerlendirilmiştir.

Çalışmada T.C. Sanayi ve Teknoloji Bakanlığı tarafindan onaylı resmi bir tasarım merkezi olan Masomo Gaming Ltd.'nin [20] (kısaca Masomo) tüm dünyada en çok oynanan mobil oyunları olan "Kafa Topu 2" ve "Basketbol Arena" oyunlarının içerdiği canlandırmaların geliştirilmesi göz önüne alınmıştır. Çalışmanın gerçekleştirildiği tarihte "Kafa Topu 2" oyunu tüm dünyada toplamda 200 milyonun üzerinde indirilmiştir ve günlük 1,5 milyon etkin oyuncusu bulunmaktadır. "Basketbol Arena" ise henüz yakın bir zamanda piyasaya sürülmesine rağmen 20 milyonun üzerinde indirilme ve günlük 350 binden fazla oynanma sayısına ulaşmıştır. Bu oyunlar Türkiye'nin sayısal oyun ihracatının büyük bir yüzdesini oluşturmaktadır [21].

\subsection{Bağlam ve Araştırma Deseni}

Masomo'da oyun geliştirme süreci oyunun genel yapısı hakkında ekibin genel bir bilgi paylaşımı gerçekleştirilmesi ile başlar. Oyun tasarımcısı tarafindan oyunun tasarım belgesi hazırlanır. Oyun içerisinde bulunan bütün özellikler ve bölümler bir tasarım belgesi olarak hem geliştirici ekiple hem de tasarım ekibi ile paylaşılır. İlgili belgede oyunun ana mekaniği, sistemler arası etkileşim, oyun oynama ekranı ve oyun içerisinde olacak her bölümü anlatan detaylı açıklamalar bulunur. Ayrıca oyunda bulunan her bölümün hangi amaçla eklendiğini ve oyunun genel yapısı için önemi anlatılır. Oyun içerisinde ön plana çıkacak alanlar belirlenir. $\mathrm{Bu}$ tasarım belgesinin paylaşılmasının ardından karakterler ve canlandırmalar karşılıklı olarak belirlenerek bunlar için gerekli olan ihtiyaçlar ortaya çıkarılır. Sanat ekibi belirlenen ihtiyaçlar doğrultusunda gerekli canlandirmaların planlamasinı yapar. Canlandırmalar anlamlarına uygun olarak zıplama, koșma, sandık açma ve benzeri șekilde adlandırılarak tasarlanan oyunun canlandırma kütüphanesine yerleştirilir. Bundan sonra ön yüze 
aktarılması için geliştirici ekip kütüphane içerisinde bulunan dosyaları kullanır. Gerekli senaryolarda harekete geçecek veya tetiklenecek canlandırmalar kütüphaneden alınarak ön yüze yerleştirilir ve canlandırmanın ilgili senaryo gerçekleştiği zaman oynatılması sağlanır. Daha önceki oyun geliştirme projelerinde bu canlandırmaların gerçeklenmesi için hareketli grafikler kullanılıp sadece $\mathrm{C}++$ dili ile kodlama yapılırken, bu çalışmada Spine canlandırma kütüphanesi kullanılmış ve kütüphane için gerekli hazırlık ve canlandırma süreçleri işletilmiştir.

Mobil aygıtlar üzerinden kullanıcıların müsabakalar sırasında kullanılabilecek süper güçlerle birbirlerine hızlı bir şekilde gol veya basket atmaya çalıştıkları bu mobil oyunlar için farklı canlandırmalar bir hareket olarak birleştirilmekte ve kütüphane çeşitlendirilmektedir. Şekil 1 ve Şekil 2 ile bu canlandırmalardan örnek ekran görüntüleri verilmiştir. $\mathrm{Bu}$ canlandırmaların tam hallerine http://shorturl.at/yDL14 adresinden erişilebilir. İskelet canlandırmaları sayesinde hazırlanan hareketler farklı karakterlere daha kolay ve hizlıca uygulanmıştır.

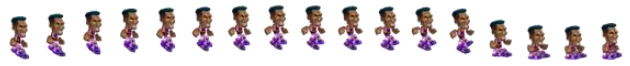

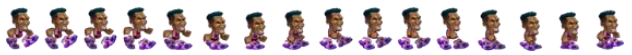

Şekil-1: Basketbol Arena oyunundan zıplama ve yürüme canlandırmalarına ait her karenin gösterimi.

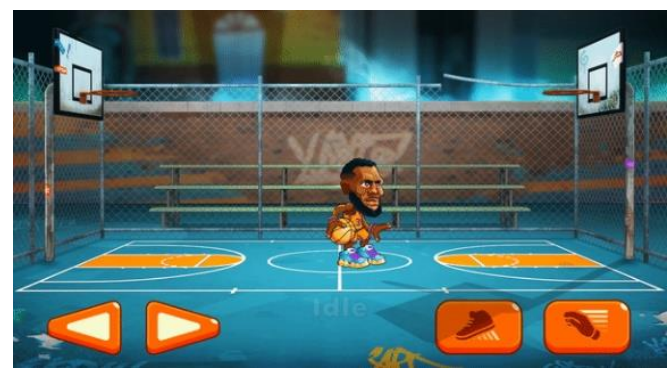

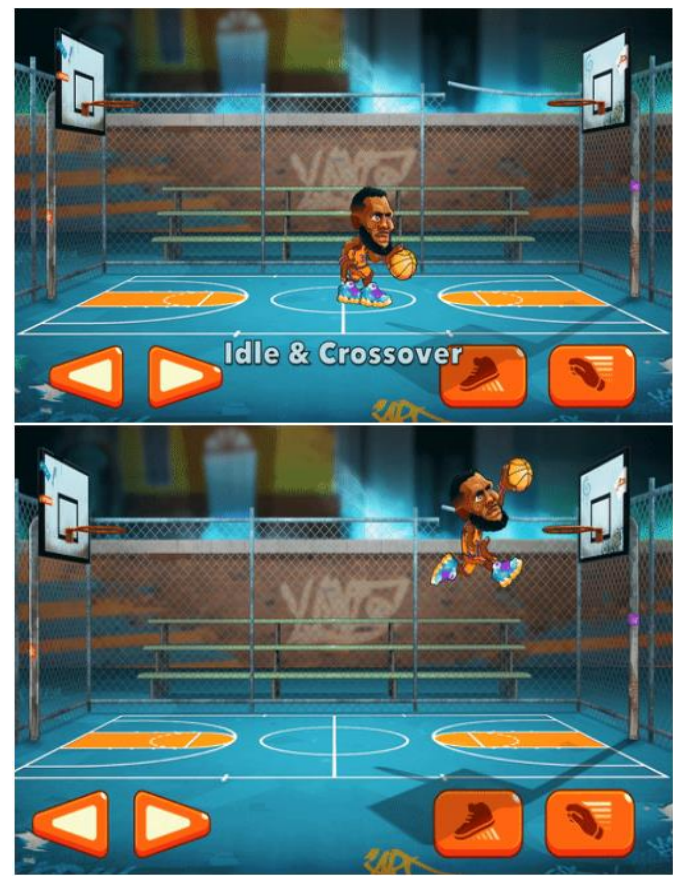

Şekil-2: Basketbol Arena oyunu için geliştirilen canlandırmalara ait örnek ekran görüntüleri

Hazırlanan canlandırmaların ilgili oyunların geliştirme süreçlerine eklenmesine örnek olarak zıplama hareketinin önceliklendirilmesi, farklı canlandırılmış örneklerin üretilmesi ve test edilmesi verilebilir. Bunun için oyunun farklı zıplama ve tek zıplama canlandırmaları içeren sürümleri üretilerek hedef marketlerde oyuncular tarafindan oynanmas1 sağlanmaktadır. Test edilen örneklerde iki sürüm arasında çok büyük bir fark yoksa burada zıplama canlandırmasını daha fazla geliştirmek için kaynak harcamaya gerek kalmamaktadır. Eğer zıplama canlandırmalarının çeşitliliği oyunda daha fazla süre geçirilmesini sağlıyor ve daha fazla kullanıcının bir sonraki gün oyunu açmasını tetikliyorsa zıplama çeşitliliği artırılmaktadır. Bu süreç canlandırma özelinde farklı şekillerde çeşitlendirilerek özellikle hangi canlandirmalara daha fazla kaynağın harcanması gerektiğinin belirlenmesini ve canlandırma kütüphanesi kullanılarak geliştirilmelerini sağlar. Sonrasında canlandırma oyuna dahil edilir. 


\subsection{Kütüphane Seçimi}

Her iki mobil oyunun da canlandırma çeşitliliğini sağlamak amacıyla farklı canlandırma yazılımı kütüphaneleri incelenmiştir. İlk olarak farklı oyun motorları desteği ve çizim aracı sunabilme ölçütleri gözetilerek gerçekleştirilen eleme sonucunda Lehtonen'in çalışmasında da [10] kullanılan Toon Boom [22] yazılımı denenmiştir. $\mathrm{Bu}$ yazılımda karakterlerin ve nesnelerin parçalarının ayrı ayrı hareket ettirilmesi tekniği ile canlandırma programları hazırlanabilmektedir. Ancak daha çok çizgi film canlandırmalarında kullanıldığı için Toon Boom yazılımının mobil oyunlar için çok önemli bir unsur olan hız açısından Spine yazılımına kıyasla daha kötü başarım gösterdiği belirlenmiştir. Ayrıca, geliştirilen yazılım testi sürecinde, özellikle canlandırma için hazırlanan JSON biçimindeki dosyanın Toon Boom kullanıldığında doğrudan oyuna aktarılamadığı tespit edilmiştir. Bunu sağlamak için farklı bir eklentinin geliştirilmesi gerekmektedir. Oyun yazılımı geliştirme ekibi bu eklentinin geliştirilmesinin yazılım istekleri açısından sağlıklı ve pratik bir çözüm olacağından emin olamamıştır. Belirlenen tüm bu eksiklikler nedeniyle Toon Boom yerine Spine yazılımı tercih edilmiştir.

Spine hem bir düzenleyici kullanarak canlandırmalar oluşturmayı hem de kendine ait çalışma zamanı kütüphanelerini kullanan oyunlarda bu canlandırmalardan faydalanmak için verimli bir iş akışı sunmaktadır. Bu yazılım ile bir canlandırma yaratmak için karakter iskeletlerine görüntüleri bağlamak ve iskeleti canlandırmak yeterlidir. $\mathrm{Bu}$ yaklaşım bilindik hareketli grafik canlandırmalarına göre karakterlerin farklı görüntülerle giydirilmesi ve farklı görsel etkiler verilebilmesi, aynı karakterin yürümeden koşmaya ya da yüzmeye pürüzsüz hareket geçişini sağlayan harmanlanmayı desteklemesi ve iskeletin kodla işlenebilmesi açılarından daha etkindir.

\section{3 Çalışma Grubu ve Veri Toplama}

"Kafa Topu 2" ve "Basketbol Arena" oyunlarının geliştirilmesi sırasında tasarımcı, yazılım geliştirici ve canlandırıcılardan oluşan toplam 42 kişilik bir proje ekibi görev almıştır. Bu ekip içerisinde 5 kişi canlandırma ve sanat grubunda, 14 kişi oyun geliştirmede, geriye kalan kişiler ise arka uç geliştirme grubundadır. Tüm ekibin endüstriyel ölçekte canlandırma ve mobil oyun geliştirme alanında ortalama 3 yıl deneyimi bulunmaktadır.
Yukarıda belirtilen tüm ekip kütüphane karşılaştırmanın sayısal değerlendirmelerine kat1lırken, canlandırma prensiplerine göre niteliksel değerlendirmeye sadece oyunların geliştirilmesinde görev alan 5 kişilik Masomo canlandırma ve sanat ekibi katılmıştır. Bu değerlendiricilerin ortalama 5 yıl Spine kullanımı deneyimi vardır. Aynı ekibin Spine'a ek olarak diğer canlandırma kütüphaneleriyle ve Toon Boom, Sprite ve benzeri bilgisayar araçlarıyla ilgili olarak da bilgi ve becerisi bulunmaktadır. Ekibin profesyonel olarak bu alanda ortalama $6,5 \mathrm{y} 1$, endüstriyel mobil yazilım geliştirme projelerinde ise ortalama 4,5 y1l deneyimi vardır.

\subsection{Verilerin Çözümlenmesi}

$\mathrm{Bu}$ değerlendirme çalışmasından elde edilen verilerin hem nitel hem de nicel çözümlemeleri gerçekleştirilmiştir. Nicel çözümleme için bir önceki alt bölümde tanitılan çalışma grubunun "Kafa Topu 2" ve "Basketbol Arena" oyunlarının geliştirilmesi sürecinden elde edilen veriler üzerinden iki boyutlu iskelet canlandırması kullanımının sağladığı yararlar belirlenmiştir. $\mathrm{Bu}$ amaçla firmada önceden kullanılan klasik oyun yazılım geliştirme teknolojisi ile elde edilen canlandirma adetleri ve Spine kullanımı ile geliştirilen canlandırma adetleri sayılmıştır. Ayrıca yine her iki farklı oyun geliştirme yaklaşımının uygulanması sonucunda canlandırmaların üretilmesi için geçen geliştirme zamanları ölçülmüştür. Hareketli grafik ve iki boyutlu iskelet canlandırması yaklaşımlarının karşılaştırılması için çalışma grubundan elde edilen geri bildirimler kullanılmıştır.

Çalışmadaki nitel çözümleme için ilgili alanda kullanılan "Canlandırmanın 12 Temel Prensibi"”ne göre Spine'ın canlandırma ve sanat ekibince değerlendirilmesi sağlanmıştır. Söz konusu bu temel prensipler hakkında daha önce bilgisi olmayan çalışma grubu üyelerine bilgi verildikten sonra sunulan bir anket üzerinden grubun hem "Kafa Topu 2" hem de "Basketbol Arena" oyunlarının geliştirilmesi sırasında Spine kullanımının bu prensipler yönünden puanlaması istenmiştir. 5'li Likert ölçeğinde alınan puanların ortalamaları hesaplanarak gerekli çözümlemeler yapılmıştır. $\mathrm{Bu}$ çözümlemeler sırasında değerlendiricilerin verdikleri puanların yanı sıra bildirdikleri puanlama gerekçeleri de kullanılmıştır. 


\subsection{Geçerliliğe Tehditler}

Her değerlendirme çalışmasında olduğu gibi bu çalışmada da 2B iskelet kütüphanesi kullanımı değerlendirmesinin geçerliliğine yönelik bazı tehditler bulunmaktadır. Bu tehditler yapısal, içsel, dışsal ve sonuç geçerliliğine yönelik olabilir [31].

Yapısal geçerlilik açısından tehditler değerlendirmenin şekli, değerlendirici seçimi veya süreç takibinde oluşabilir. Her ne kadar ilgili yazılım aracının kullanımına yönelik genel yarar ve sakıncaların belirlenmesinde geri bildirimlerinden yararlanılan proje ekibindeki kişi sayısı yeterli görünse de özelde canlandırmanın 12 temel prensibine göre Spine'in değerlendirilmesi çalışmasında değerlendirici olarak katılım gösteren sanat ekibindeki kişi sayısı birçok değerlendirme çalışmasına kıyasla daha az sayıdadır. Buradaki temel neden Spine gibi nispeten yeni bir kütüphanede çalışan oyun geliştirici sayısının azlığıdır. Ayrıca bu çalışma için değerlendirici olarak doğrudan mobil oyun alanında deneyimli, aktif olarak çalışan ve ticari ürün geliştirmede de Spine kullanan kişilerin seçilmesine dikkat edilmiştir. Bu seçim de yine değerlendirici sayısını kısıtlamıştır. Yine de kullanım çalışmaları için Nielsen ölçeği düşünüldüğünde bu çalışmaya dahil olan değerlendirici sayısı yeterli görünmektedir [32].

Tek değerlendirici grubu oluşturulması bir içsel geçerlilik tehdidi olarak görülebilir. Aynı değerlendirici grubu hem klasik programlama ile hem de Spine kullanımı ile aynı oyunların geliştirilmesi süreçlerini değerlendirmişlerdir. Tek bir değerlendirici grubun kullanılmas1 değerlendiricilerin önceki klasik yöntemdeki deneyimlerini Spine kullanımını içeren yeni yönteme de yansitmasina ya da tam tersine neden olabilir. Canlandırma geliştirmede sadece klasik kodlamay1 uygulayan bir grup ile sadece Spine'1 kullanan bir grubun karşılaştırılması bu riski azaltabilir. Ancak bu sefer de kullanıcı geri bildirimine dayalı nitel değerlendirmelerin yapılması mümkün olmayacaktır. Özellikle $4.1,4.2$ ve 4.3 bölümlerindeki sonuçların elde edilmesinde her iki canlandırma geliştirme yöntemini de kullanan değerlendiricilerin bulunması fayda sağlamıştır.

Dışsal geçerlilik elde edilen sonuçların ne kadar genelleştirilebileceği ile ilgilidir. $\mathrm{Bu}$ çalışmadaki dışsal geçerlilik tehdidi Spine ile geliştirilen mobil oyun sayısıdır. Sadece iki adet mobil oyun geliştirme süreci üzerinden Spine kullanımı değerlendirilmiştir. Ancak her iki oyunun da kapsam ve karmaşıklıkları Spine'in kullanımının göz önüne alındığı önceki çalışmalara kıyasla çok daha fazladır. İçerdikleri canlandırmaların sayı ve kalitelerinin bu ticari oyunların milyonlarca kullanıcısını tatmin edecek düzeyde olması gereksinimi de düşünüldüğünde bu oyunlar üzerinden gerçekleştirilen nitel değerlendirmelerin ve canlandırma prensiplerine göre puanlamanın genele hitap ettiğine inanılmaktadır.

Son olarak bu çalışmadan elde edilen sonuçların geçerliliğinin yine geliştirilmeleri göz önüne alınan mobil oyunların sayısına, kapsamına ve uygulanan geliştirme süresine özel olduğunu belirtmek gerekmektedir. Oyun yazılımı ihtiyaçlarının değişmesi durumunda canlandırma üretme adedi değişkenlik gösterebilir. Ayrıca yine hem geliştirilecek oyuna hem de tasarımcıların veya canlandırıcıların yeteneğine ve becerisine bağlı olarak canlandırma üretme süreleri farklı olabilir. Ancak gerçekleştirilen çalışmada oyunların ihtiyaç duyduğu canlandırmalar karmaşıklaştıkça iki boyutlu iskelet canlandirma kütüphanesi kullanılarak gerçekleştirilen canlandırmaların sayı ve kalitesinin daha yüksek oranda arttığı belirlenmiştir. $\mathrm{Bu}$ sonuç kütüphane kullanımının kodlamaya k1yasla her zaman canlandırma üretiminde miktarı arttıracağını ve süreci hızlandıracağını açıkça göstermektedir. Fakat üretim adedindeki hızlı artışın ve geliştirme süresindeki azalmanın geçerliliğinin daha iyi ortaya konulması için daha fazla sayıda oyun geliştirme süreci üzerinde çoklu durum çalışmalarının gerçekleştirilmesine ihtiyaç vardır.

\section{Bulgular}

\section{1 İki Boyutlu İskelet Canlandırması Kullanımının Sağladığı Yararlar}

Canlandırma kütüphanesinin ilgili oyunlarda kullanımı sonrasında edinilen yararlar aşağıdaki gibi stralanabilir.

- 2B iskelet canlandırma kütüphanesinin sunduğu 1zgara özelliği ile tek bir JPEG biçimindeki görüntü dosyası üzerinde bir canlandırmaya ait çeşitli pozların bir arada konumlandırılması mümkün olmuştur. Böylece oyunlar içerisinde oluşturulan toplam dosya boyutunun azaldığ gözlenmiştir. $\mathrm{Bu}$ özellik mobil oyun 
geliştiricileri için gerçekten önem arz etmektedir.

- Hazırlanan her bir canlandirmanın son haline yakın sürümleri oyuna aktarılmadan önce Spine yazılımı içerisinde ön izleme ile oynatılmakta ve test edilebilmektedir. Böylece canlandırma oluşturma süreci hızlanmıștır.

- JPEG biçiminde oluşturulan görüntü dosyalarının renk değişimi Spine yazılımı ile hızlıca gerçekleştirilmiştir.

- Bir oyun karakteri yere düştüğünde ses çıkması gibi canlandırma sırasında gerçekleșmesi istenen olayların tetiklenmesini mümkün hale getiren yazılıma ait mekanizmalar ile ekip içerisinde canlandırıcıların geliştiricilere yapılmak istenen canlandırma kurgusunu planlı bir şekilde ve çok kısa sürelerde aktarabilmesini sağladığı gözlenmiştir.

- Canlandirıcıların bir sayısal modeli hareket ettirebilmeyi mümkün kılan denetimleri içeren üç boyutlu giydirme hareketlerini iki boyutlu yazılıma aktarmaları Spine ile çok kolaylaşmıştır.

- Spine kaplamaları aynı canlandırmanın birden fazla karakterde görülmesini ve hizlica uygulanmasını sağlamıștır. Bu özellik daha fazla sayıda ve çeşitte karakterlerin üretilmesine imkân vermiștir.

- Hareketli grafik yerine 2B iskelet canlandırma kullanılması özellikle oyun geliştirme ekibindeki sanat grubunun etkinliğini arttırmıștır. Az ya da hiç kodlama bilgisi olmayan sanat grubu üyeleri ürün çıkarırken Spine yazilımindan yararlanabilmektedir. Değerlendirmeye katılan Masomo Gaming ekibi bu etkinliğin geliștirilen ürünün kalitesine çok büyük oranda etki ettiğini ve hareketli grafiklerle hazırlanan canlandırmalara göre estetik algısının çok daha iyi yansıtıldığını belirtmişlerdir.

Listelenen nitel değerlendirme sonuçlarına ek olarak bu çalışmada 2B iskelet canlandırma kullanımının oyun yazılımı projelerindeki nicel kazancı da canlandırma geliștirme zamanı ve geliștirilen canlandırma adedi üzerinden belirlenmiștir. Oyun yazılım geliștirme sürecindeki bölüm tasarımı ve canlandırma hazırlama adımları arasındaki toplam sürenin bir canlandırmanın hazırlanması için salt $\mathrm{C}++$ kodlama içeren hareketli grafiklere göre yaklaşık \%65 daha kısa sürdüğü belirlenmiştir. Spine yazılımının sağladığı programlama imkanları haricinde sanat grubunun geliştirme adımlarına çok daha rahat tümleştirme ve çeşitlilik çıkarması bu sonuca etki etmiştir.

Çizelge 1 ile her iki oyun için altı aylık geliştirme süreci içerisinde kodlamaya dayalı klasik hareketli grafik yaklaşımı ile 2B iskelet canlandırma kullanımını içeren yöntemin uygulanması sonucunda elde edilen canlandirma adetleri verilmiștir. Buna göre "Kafa Topu 2" için 7 kat üretim başarımı sağlanırken, "Basketbol Arena" oyununda bu oran yaklaşık 17 kata çıkmıștır. Ortalamada yaklaşık 12 kat olan bu üretim oranı daha önce gerçekleştirdiğimiz değerlendirmeye [12] göre çok daha fazladır. Üstelik "Basketbol Arena" oyunu "Kafa Topu 2" oyununa kiyasla oyun içerisinde rakiple birebir mücadele ederken atışları engelleme, hizlı geri ve ileri manevralar gibi karmaşık oynama dinamikleri gerektirmektedir. Bunları sağlayacak canlandırmaların karmaşıklık düzeyi de daha yüksektir. Buna rağmen iskelet canlandirmaları "Basketbol Arena" oyununda canlandırma sayısını daha büyük oranda arttırmıştır. $\mathrm{Bu}$ sonuçlarla oyun yazılımı geliştirmede elde edilen hızın yanı sıra üretim miktarı açısından da Spine kullanımı verim sağlamıştır denebilir.

Çizelge 1: Geliştirilen canlandırma adedi karşılaştırması

\begin{tabular}{|c|c|c|}
\hline & $\begin{array}{c}\text { Klasik } \\
\text { Yöntem }\end{array}$ & $\begin{array}{c}\text { Spine } \\
\text { Kullanımı }\end{array}$ \\
\hline Kafa Topu 2 & 10 & 70 \\
\hline $\begin{array}{c}\text { Basketbol } \\
\text { Arena }\end{array}$ & 5 & 84 \\
\hline
\end{tabular}

\subsection{Hareketli Grafik ve İki Boyutlu İskelet Canlandırması \\ Yaklaşımlarının Karşılaştırılması}

Hareketli grafik, canlandırma için kullanılan en eski yaklaşımlardan biridir, fakat bir canlandırma için gereken her kare ayrı ayrı çizildiğinden her kare uygulama belleğinde ayrı bir yer tutar. Canlandırma çeşitliliği arttığında kullanılan disk alanı ve çalışma sırasındaki bellek kullanımı artar. Mobil aygitların kısıtlı disk alanları ve düşük bellekleri sebebiyle bu ortamlar için hazırlanan oyunlar bu özelliklere dikkat etmektedirler.

2B iskelet canlandırması yaklaşımı ise bir iskelet üzerindeki her uzuv için bir grafik kullanır ve bu 
uzuvların hareketlerini belirli pozlar arasında hareket ettirir. Her uzvun ayrı olması kullanılan grafik sayısını arttırırken toplam boyutu düşürmektedir. Ayrıca iskelet üzerinde hazırlanmış bir canlandırma farklı karakterlerin iskeletleri üzerinde uygulanabilir. $\mathrm{Bu}$ sayede görünümü farkl1 karakterler, farklı parametrelerle, örneğin daha hızlı bir şekilde, bu canlandırmayı kullanabilirler.

Hareketli grafiklerde bellek kullanımı hızlıca artarken, 2B iskelet canlandırma yaklaşımında da oyun sahnesinde yer alan karakter sayısı arttıkça işlemci yükü artmaktadır. $\mathrm{Bu}$ da mobil oyunlarda diğer bir kısıt olan ișlemci kullanımı ve pil ömrünü etkilemektedir. Ayrıca, hareketli grafiklerdeki canlandirmalar hem daha estetiktir hem de her karenin ayrı çizilmesinden ötürü iskelet canlandırması ile elde edilemeyecek görüntü çeşitlilikleri ile bunlar zenginleştirilebilir.

Oyundaki karakterlerin ve karakter başına düşen canlandırmaların sayısı göz önüne alınarak uygun yaklaşım tercih edilebilir. Hareketli grafikler her kareye özel çizimlerle estetik görüntüler sağlayabilirken, iskelet canlandırmaları daha az bellek kullanımı ve canlandırmaların farklı karakterlerde kullanılması ile öne çıkmaktadır.

\subsection{Canlandırma Prensiplerine Göre Değerlendirme}

Disney canlandirıcilarından Johnston ve Thomas'in tanıttıkları "Canlandırmanın 12 Temel Prensibi" yayınlandığı tarihten bu zamana kadar canlandırma tekniklerindeki birçok yeniliğe rağmen günümüzde hala geçerliliğini korumaktadır [13], [23], [24]. Bu prensipler canlandırmanın kullanıldığı üç boyutlu modelleme, oyun programlama, robotik gibi birçok alandaki çalışmada hem uygulama hem de değerlendirmede kullanılmaktadır [25]-[29]. Aşağıda bu prensipler kısaca özetlenmiştir. Her bir prensibin uygulandığı örnek canlandırmalara [30] kaynağından ulaşılabilir.

1. Ezilme ve Esneme: Bir nesnenin hareket öncesinde ezilmesi ya da sıkışması ve hareket sonrasında esnemesi. Örneğin, bir topun ziplamas1.

2. Öngörme: Bir sonraki hareket için hazırlığı sağlayan hareket. Örneğin, zıplamadan önce biraz eğilme ya da yumruk atma öncesi kolun geriye alınmas1.
3. Sahneleme: Bir sahnenin izleyiciler tarafindan kolayca anlaşılması için karakter duruşu, kamera açısı ve diğer tüm sahne ayarlarının gösterimi.

4. Dosdoğru ve Pozdan Poza Hareket: Dosdoğru hareket en baştan itibaren kesintisiz bir hareketi belirtirken pozdan poza bir sahnenin canlandırılması öncesi her adımın belirlenmesini göz önüne alır ve hareketler daha planlıdır. Dosdoğru hareketler daha gerçekçi eylem sırasının oluşturulmasını sağlamakla birlikte uygulamaları daha zahmetlidir. Öte yandan pozdan poza hareketlerin hazırlanışı daha kolaydır ve genellikle dramatik sahneler için uygundur.

5. Devamlı ve Örtüşen Hareket: Bir nesne ya da karakterin fizik kurallarına uygun olarak durması. Örneğin, aniden duran bir kișinin uzuvlarının aynı hızda durmaması ya da esnek dikdörtgen bir nesnenin hareket halindeyken alttan durdurulduğunda üst kısmının salınım hareketi yapmas1.

6. Yavaș Başlama ve Durma: Canlandırmalarda hareketlerin başlangıç ve bitişlerinin hareket ortasına göre daha yavaş olması. Bir başka deyişle karakter ya da nesnelerin yavaş yavaş hızlanması ve aşamalı olarak durmaları.

7. Kavis Çizme: Düz hareketler yerine daha gerçekçi çizimler için hareketlerin dairesel ya da kavisli bir biçimde yorumlanması.

8. İkincil Hareket: Canlandırmada bir ana hareketi tamamlayan ve etkisini arttıran ek hareket.

9. Zamanlama: Bir karakter ya da nesnenin hareketinin gerçekleştirilmesi için gerekli kare sayıs1.

10.Abartma: Göze daha hoş gelen etkileyici canlandırmaların sağlanması için karakter ve nesne hareketlerinin ya da ifadelerinin abart1lmas1.

11.Sağlam Çizim: Canlandırmanın her karesinde çizimlerin ilgili karakter ya da nesneyi yeterince hacimli, derinlikli ve sağlam gösterecek bir bakış açısında oluşturulması.

12.Cazibe: Bir nesne ya da karakterin canlandırmada daha ilgili çekici bir halde gösterilmesi.

Önceki 4.1 ve 4.2 bölümlerinde sonuçları verilen 
genel değerlendirmeye ek olarak canlandırma kütüphanesinin mobil oyunların geliştirilmesi sırasında yukarıdaki temel canlandırma prensiplerini ne derece desteklediği ile ilgili bir değerlendirme gerçekleştirilmiştir.

Değerlendiriciler canlandırmanın 12 temel prensibini göz önüne alarak Spine yazılımının sunduğu özellikleri, 1 puan: çok kötü, 5 puan: çok iyi, olmak üzere 5'li Likert ölçeğini kullanarak puanlamıştır ve puan gerekçelerini kısaca belirtmişlerdir. Bir prensibin Spine yazılımı için geçerli olmadığını düşündükleri ya da puanlamak istemedikleri prensipleri 0 puan ile belirtmişlerdir. Bu durumda sadece ilgili prensip için 1-5 puan aras1 verilen puanların ortalaması alınmıştır. Çizelge 2'de tüm ekibin her bir prensip için verdiği puanların ortalaması listelenmiştir.

Çizelge 2: Spine kütüphanesinin
“Canlandırmanın 12 Temel Prensibi”ne göre 5'li
Likert ölçeğinde değerlendirilmesi
\begin{tabular}{|c|c|c|}
\hline $\begin{array}{c}\text { Canlandırmanın } \\
\text { 12 Temel } \\
\text { Prensibi }\end{array}$ & $\begin{array}{c}\text { Kafa Topu } \\
\mathbf{2}\end{array}$ & $\begin{array}{c}\text { Basketbol } \\
\text { Arena }\end{array}$ \\
\hline $\begin{array}{c}\text { Ezilme ve } \\
\text { esneme }\end{array}$ & 4 & 5 \\
\hline Öngörme & 3 & 5 \\
\hline Sahneleme & 1 & 1 \\
\hline $\begin{array}{c}\text { Dosdoğru ve } \\
\text { Pozdan Poza } \\
\text { Hareket }\end{array}$ & 3 & 3 \\
\hline $\begin{array}{c}\text { Devamlıve } \\
\text { Örtüşen Hareket }\end{array}$ & 4 & 4 \\
\hline $\begin{array}{c}\text { Yavaş Başlama ve } \\
\text { Durma }\end{array}$ & 5 & 5 \\
\hline Kavis Çizme & 2 & 3 \\
\hline Ikincil Hareket & 3 & 3 \\
\hline Zamanlama & 5 & 5 \\
\hline Abartma & 0 & 0 \\
\hline Sağlam Çizim & 5 & 5 \\
\hline Cazibe & 0 & 0 \\
\hline
\end{tabular}

Çizelgede verilen puanlar yorumlandığında ilk olarak ezilme ve esneme prensibini sağlamak açısından Spine yazılımının her iki oyun geliştiriminde de değerlendiricilerden iyi not aldığ 1 görülmektedir. Değerlendiricilerin genel kanıs1 canlandırmalarda PNG biçimindeki görüntülerin 1zgara yapılarına uygulanması ne kadar düzgün olursa ezilme ve esnemenin o derece iyi olacağıdır. Spine yazılımı da bu konuda kaliteli 1zgara uygulamaya elverişli bir program olarak belirlenmiştir. Değerlendiriciler bu nota etki eden bir diğer etkenin Spine yazılımının giydirme sisteminin daha önce deneyimledikleri kütüphanelere kıyasla daha gelişmiş olması, üç boyutlu yapıyı desteklemesi ve böylece canlandırmaya kolaylık sağlaması olarak belirtmişlerdir.

Öngörme desteğinin her iki oyun göz önüne alındığında yine ortalamada iyi olarak değerlendirildiği söylenebilir. Öte yandan Spine yazılımının sahneleme desteği tüm kullanıcılar tarafından yetersiz bulunmuştur. Gerekçe olarak genellikle yazılımın herhangi bir araç desteğinin olmadığ 1 ve sahne için kamera kullanımına dair bir özelliği sağlamadığı belirtilmiştir.

Spine yazılımının dosdoğru ve pozdan poza hareket desteği için değerlendiriciler iskelet canlandırması olan her programda olduğu gibi Spine yazılımının da pozdan poza geçerken ara kareleri tamamladığını büyük oranda teyit etmişlerdir. Ancak, hareketli grafik mantığındaki gibi, bunun çok büyük oranda bir hareket imkânı tanımadığını belirtmişlerdir. Farklı hareket eksenlerine geçmek istense de bunun için fazladan bir çizim dosyasına ve kaliteli bir 1zgara uygulamasına ihtiyaç vardır. Bu nedenlerden dolayı bu prensip için Spine yazılımı ortalama bir puan almıştır.

Yavaş Başlama ve Durma yeteneği için Spine yazılımının yerleşik bir grafik düzenleyici sunması gerekçe gösterilerek bu prensip için değerlendiricilerin her iki oyun geliştirmede de yazılıma tam puan verdikleri görülmektedir. Söz konusu olan yavaş hızlanma ve kademeli yavaşlama yazılım içerisindeki düzenleyici ile sağlanmaktadır ve bu canlandırıcıların ișini çok kolaylaştırmaktadır.

Değerlendiriciler açısından doğrusal hareketlere kıyasla Spine yazılımı ile kavis çizme desteğinin kısitlı bulunduğu verilen puanlardan görülmektedir. Bunun ana nedeni genellikle kemiklerin mükemmel bir kavise yerleştirilmesinin pek mümkün olmaması ve mutlaka kırılma veya patlamaların meydana gelmesi olarak gösterilmiştir. Bir kısım değerlendirici kavis içeren hareketler için yazılımda buna uygun giydirme çözümlerinin ve ağırlık boyamalarının yararlı olabileceğini belirtmişlerdir.

Zamanlama, Spine yazılımının en yüksek puan aldığı 
bir diğer prensiptir. Değerlendiriciler bu sonuca en büyük etkenin yazılımda zamanlamayı gösteren basit bir ara yüzün bulunmasını ve bu ara yüz üzerinden çok rahatça ana kareler atılarak bunların zamanlamasının ayarlanabilmesini göstermiştir. Buna ek olarak grafik düzenleyicide yapılan bir eylemin doğrudan bu zamanlama ara yüzünde de gösterilmesi ve böylece uygulamanın hangi iki kare arasında eylem alındığını görsel olarak sunması da güzel ve faydalı olarak nitelendirilmiştir.

İkincil hareket desteği için Spine yazılımında bir fizik yapısının bulunması ekibin bir kısmı tarafindan olumlu bulunmuştur. Genel olarak değerlendiriciler bir karakterin hareketlendirilmesi yapıldıktan sonra ikincil harekete sahip olacak yüzeylerin hareketlendirilmesinin o hareketin ekseni hesaplandıktan sonra yazılımda sağlandığını belirtmişlerdir. Ancak bu desteğin aynı zamanda çoğu zaman yanlış çalıştığı ve el ile bir düzenleme gerektirdiği de belirtilmiştir. Bir değerlendirici ise bu çoğu zaman müdahale gerektiren ikincil hareket desteğinin yazılımda bulunmasının önemli olduğunu çünkü iki boyutlu canlandırma yazılımlarında zaten ikincil hareket için hazır bir fizik yapısının kolay kolay bulunmadığını ifade etmiştir.

Tüm değerlendiriciler Spine yazılımının canlandırmadaki üç boyut etkisini ve derinliği sağlama özelliğini yeterli bulmuşlardır. Buna bağlı olarak sağlam çizim prensibi açısından yazılıma tam not vermişlerdir. Bu desteği Spine yazılımının ızgara uygulama sisteminin sağladığı belirtilmiştir.

Son olarak kullanıcılar Spine yazılımının canlandırmalarda abartma ve cazibe için bir altyapı sağladığını düşünmekle birlikte aslında bu prensipler açısından yazılımın puanlanmasının uygun olmadığı görüşündedir. Bunun nedeni değerlendiricilerin genel olarak canlandırmalar için her iki prensibin sağlanmasının doğrudan canlandırıcıların yaratıcılığı ve yeteneğine bağlı ve canlandırma programından bağımsız olduğunu, dolayısıyla herhangi bir programda sağlanabileceğini düşünmeleridir.

\section{Sonuçlar}

$\mathrm{Bu}$ çalışmada iki boyutlu iskelet canlandırma kütüphanesinin dünyada en çok oynanan iki mobil oyunun geliştirilmesi sırasında kullanılmasının bir değerlendirilmesi gerçekleştirilmiştir. Değerlendirme sonuçları kütüphanenin sunduğu 1zgara yapıs1 ile bir canlandırmaya ait pozların konumlandırmasını kolaylaştırdığını, aynı canlandırmanın birden fazla karakterde görülmesini ve hızlıca uygulanmasını sağladığını, geliştirme ekibindeki canlandırıcıların, oyun geliştiricilerine yapılmak istenen canlandırma kurgusunu çok kısa sürelerde aktarılmasına imkân verdiğini göstermiştir. Ayrıca oyunlardaki canlandırmaların kodlamaya bağlı klasik yöntemlerle geliştirilmesine kıyasla Spine kullanımının canlandırma üretimini ortalamada yaklaşık 12 kat arttırdığı ve canlandırma geliştirme sürecini yine yaklaşık \%65 kısalttığı belirlenmiştir. Öte yandan hareketli grafiklerin her karesinin çizilmesi, iskelet canlandırma yaklaşımına göre daha estetik sonuçlar verdiği ve iskelet canlandırmanın sahnedeki karakter sayısı arttıkça işlemciye daha çok yük getirdiği tespit edilmiştir. Son olarak, canlandırmanın temel prensiplerine göre yapılan değerlendirme ise çalışmaya katılan değerlendiricilerin canlandırılan karakterler ve nesneler için özellikle ezilme ve esneme, yavaş başlama ve durma, zamanlama ve sağlam çizim desteğini güçlü bulurken sahneleme ve kavis çizimlerinde Spine yazılımını yetersiz gördüklerini göstermiştir. Canlandırmalarda abartma ve cazibeyi sağlamaya ise Spine kullanımının bir katkısı bulunmamıştır.

$\mathrm{Bu}$ çalışmanın devamında ilk olarak elde edilen sonuçların genelleşmesini sağlayacak yeni değerlendirme çalışmalarının gerçekleştirilmesi hedeflenmektedir. $\mathrm{Bu}$ çalışmalarda iki boyutlu iskelet canlandırma kütüphanelerinin farklı ölçek ve kapsamdaki mobil oyunların geliştirilmesinde kullanılmasının değerlendirilmesi sağlanacaktır. Söz konusu bu değerlendirme çalışmalarının kurgulanmasında daha önce birçok başka yazılım ürünü ve sürecini nitel ve nicel yönden değerlendirmek için geliştirdiğimiz çoklu durum çalışması yönteminin bir uyarlamasının uygulanması düşünülmektedir [33]-[37].

Öte yandan özellikle oyun tasarımcısı ve canlandırıcıların başta yazılım ihtiyaçları, yazılım yapılandırılması ve yazılım yönetimi olmak üzere oyun yazılımlarını geliştirmeye yönelik görüşlerini çözümlemeye yardımcı olan [6]'daki çalışmadan yine Spine canlandırma kütüphanesinin bu yönde değerlendirilmesi sürecinde de yararlanılması olasidir.

Ayrıca ilerideki çalışmalarda geleneksel ve iskelet canlandırma kütüphanesi kullanılarak elde edilen 
canlandırmaların oyunu oynayanlar tarafindan da değerlendirilmesi geliştirici ve sanat ekiplerine farklı bir bakış açısı kazandırması açısından değerli olacaktır.

\section{Kaynakça}

[1] R. Ramadan ve Y. Widyani, "Game development life cycle guidelines", içinde 2013 International Conference on Advanced Computer Science and Information Systems (ICACSIS), Eyl. 2013, ss. 95100. doi: 10.1109/ICACSIS.2013.6761558.

[2] E. Adams, Fundamentals of game design. Pearson Education, 2014.

[3] A. Osborne O'Hagan, G. Coleman, ve R. V. O'Connor, "Software Development Processes for Games: A Systematic Literature Review", içinde Systems, Software and Services Process Improvement, Berlin, Heidelberg, 2014, ss. 182-193. doi: 10.1007/978-3-662-43896-1_16.

[4] M. Borg, V. Garousi, A. Mahmoud, T. Olsson, ve O. Stålberg, "Video Game Development in a Rush: A Survey of the Global Game Jam Participants", IEEE Trans. Games, c. 12, sy 3, ss. 246-259, Eyl. 2020, doi: 10.1109/TG.2019.2910248.

[5] C. M. Kanode ve H. M. Haddad, "Software Engineering Challenges in Game Development", içinde 2009 Sixth International Conference on Information Technology: New Generations, Nis. 2009, ss. 260-265. doi: 10.1109/ITNG.2009.74.

[6] E. Murphy-Hill, T. Zimmermann, ve N. Nagappan, "Cowboys, ankle sprains, and keepers of quality: how is video game development different from software development?", içinde Proceedings of the 36th International Conference on Software Engineering, New York, NY, USA, May. 2014, ss. 1-11. doi: $10.1145 / 2568225.2568226$.

[7] B. Berg Marklund, H. Engström, M. Hellkvist, ve P. Backlund, "What Empirically Based Research Tells Us About Game Development", Comput. Games J., c. 8 , sy 3, ss. 179-198, Ara. 2019, doi: 10.1007/s40869-019-00085-1.

[8] J. Gregory, Game engine architecture. crc Press, 2018.

[9] Unity, "Unity - Manual: Sprites". https://docs.unity3d.com/Manual/Sprites.html (erişim Kas. 12, 2021).

[10] J. Lehtonen, "From 2D-sprite to skeletal animation: boosting the performance of a mobile application", Turun ammattikorkeakoulu, 2016.

[11] Esoteric Software, "Spine: Oyunlar için 2 Boyutlu İskelet Animasyonu". http://tr.esotericsoftware.com/ (erişim Kas. 12, 2021).

[12] M. Tepekule, E. Şimşirli, M. A. Sakarya, R. Diriman, ve G. Kardaş, "Spine Animasyon Kütüphanesinin Oyun Yazılımı Geliştirmede Kullanımı Deneyimi”, içinde 14. Ulusal Yazılım Mühendisliği Sempozyumu (UYMS 2020), Eki. 2020, ss. 1-5. doi: 10.1109/UYMS50627.2020.9247012.

[13] F. Thomas ve O. Johnston, "The Illusion of Life: Disney Animation. Disney Editions". 1995.

[14] R. Ciesla, "Mostly codeless game development", Berkeley CA Apress, 2017.

[15] K. Myller, "Use of Spine software in video game character creation", Karelia University of Applied Sciences, 2018.

[16] P. Stacey ve J. Nandhakumar, "A temporal perspective of the computer game development process", Inf. Syst. J., c. 19, sy 5, ss. 479-497, 2009, doi: 10.1111/j.1365-2575.2007.00273.x.

[17] C. Mihale-Wilson, P. Felka, O. Hinz, ve M. Spann, "The Impact of Strategic Core-Component Reuse on Product Life Cycles”, Bus. Inf. Syst. Eng., Haz. 2021, doi: 10.1007/s12599-021-00706-y.

[18] A. Ubillis, "Evaluation of Sprite Kit for iOS game development", Linköpings universitet, 2014.

[19] Apple, "SpriteKit", Apple Developer. https://developer.apple.com/spritekit/ (erişim Kas. 12, 2021).

[20] Masomo, "Masomo". https://www.masomo.com/ (erişim Kas. 12, 2021).

[21] "Türkiye oyun sektörü nasıl yabancı yatırımcının gözdesi haline geldi? - BBC News Türkçe”. Erişim: Kas. 12, 2021. [Çevrimiçi]. Erişim adresi: https://www.bbc.com/turkce/haberler-dunya54275482\#: :text=T\%C3\%BCrkiye'de\%20oyun\%20 geli\%C5\%9Ftirici\%20\%C5\%9Firket,5\%20milyar\% 20dolar\%C4\%B1\%20ge\%C3\%A7mesi\%20bekleniy or.

[22] A. Phillips, Animate to Harmony: The Independent Animator's Guide to Toon Boom. CRC Press, 2014.

[23] J. Cooper, Game anim: video game animation explained. CRC Press, 2021.

[24] T. P. Thesen, "Reviewing and Updating the 12 Principles of Animation", Animation, c. 15, sy 3, ss. 276-296, Kas. $2020, \quad$ doi: $10.1177 / 1746847720969919$.

[25] G. Stuart, "Basic Animation", içinde Introducing JavaScript Game Development, Springer, 2017, ss. 83-92.

[26] T. M. Soikun ve Ag. A. Ag. Ibrahim, "Kansei Engineering Approach in Designing Appealing Computer Animation Character", içinde Proceedings of the 7th International Conference on Kansei Engineering and Emotion Research 2018, Singapore, 2018, ss. 470-478. doi: 10.1007/978-981-10-86120_49.

[27] N. Amani ve A. Yuly, "3D modeling and animating of characters in educational game", içinde Journal of Physics: Conference Series, 2019, c. 1193, sy 1, s. 012025 . 
[28] H. Wilander, "Player experience from 3D game components: A theoretical and empirical look at computer graphics in practice", Linköping University, 2019.

[29] T. Ribeiro ve A. Paiva, "The Practice of Animation in Robotics", içinde Modelling Human Motion: From Human Perception to Robot Design, N. Noceti, A. Sciutti, ve F. Rea, Ed. Cham: Springer International Publishing, 2020, ss. 237-269. doi: 10.1007/978-3030-46732-6_12.

[30] J. Ritchie, "The 12 Principles of Animation (With Examples)", IdeaRocket, Tem. 19, 2017. https://idearocketanimation.com/13721-12principles-of-animation-gifs/?nab $=0$ (erişim Kas. 13, 2021).

[31] C. Wohlin, P. Runeson, M. Höst, M. C. Ohlsson, B. Regnell, ve A. Wesslén, Experimentation in software engineering. Springer Science \& Business Media, 2012.

[32] J. Nielsen, "How many test users in a usability study", Nielsen Norman Group, c. 4, sy 06, 2012.

[33] M. Challenger, G. Kardas, ve B. Tekinerdogan, "A systematic approach to evaluating domain-specific modeling language environments for multi-agent systems", Softw. Qual. J., c. 24, sy 3, ss. 755-795, Eyl. 2016, doi: 10.1007/s11219-015-9291-5.

[34] S. Arslan ve G. Kardas, "DSML4DT: A domainspecific modeling language for device tree software", Comput. Ind., c. 115 , s. 103179, Şub. 2020, doi: 10.1016/j.compind.2019.103179.

[35] T. Z. Asici, B. T. Tezel, ve G. Kardas, "On the use of the analytic hierarchy process in the evaluation of domain-specific modeling languages for multi-agent systems", J. Comput. Lang., c. 62, s. 101020, Şub. 2021, doi: 10.1016/j.cola.2020.101020.

[36] A. Khalilipour, M. Challenger, M. Onat, H. Gezgen, ve G. Kardas, "Refactoring Legacy Software for Layer Separation”, Int. J. Softw. Eng. Knowl. Eng., c. 31 , sy 02 , ss. 217-247, Şub. 2021, doi: $10.1142 / \mathrm{S} 0218194021500066$.

[37] O. F. Alaca, B. T. Tezel, M. Challenger, M. Goulão, V. Amaral, ve G. Kardas, "AgentDSM-Eval: A framework for the evaluation of domain-specific modeling languages for multi-agent systems", Comput. Stand. Interfaces, c. 76, s. 103513, Haz. 2021, doi: 10.1016/j.csi.2021.103513. 